\title{
ACTIVATION PROPERTIES OF AMBIENT AEROSOL IN THE NETHERLANDS
}

\author{
A. KHLYSTOV, G. P. A. KOS and H. M. TEN BRINK \\ Netherlands Energy Research Foundation (ECN), P.O. Box 1, 1755 ZG Petten, The Netherlands \\ and \\ C. KRUISZ and A. BERNER \\ Institut für Experimentalphysik der Universität Wien, Vienna, Austria
}

(First received 5 September 1995 and in final form 6 February 1996)

\begin{abstract}
A cloud chamber has been used to study the cloud activation of ambient aerosol in The Netherlands. The large dimensions and throughput of the chamber allowed unperturbed collection of acrosol and droplets with cascade impactors and on-line measurements with cloud monitors (FSSP) inside the facility. The study provided maxima for the number of man-made aerosol acting as cloud nuclei in marine clouds in The Netherlands. Emphasis was given to the investigation of cloud formation in marine air, since sensitivity studies had shown that such clouds are most effectively influenced by the (extra) anthropogenic aerosol particles. For this reason the supersaturations in the study were low (on average $0.12 \%$ ), similar to those in actual marine stratus.

The effect of the anthropogenic aerosols on cloud formation was determined by comparing the number of droplets formed in "clean" arctic marine air to the number of droplets formed in "polluted" marine air (air which had travelled over the U.K.). Air masses with the total aerosol number concentration of the order of $100 \mathrm{~cm}^{-3}$ were considered as "clean" marine air. Air masses with higher aerosol concentrations were divided into "moderately" and "heavily" polluted with total aerosol concentrations of the order of 1000 and $10,000 \mathrm{~cm}^{-3}$, respectively.

In the clean marine air all potential cloud nuclei (particles larger than the threshold size of the smallest reference particles that were activated at a given supersaturation) were activated and the number of cloud droplets formed was on average $45 \mathrm{~cm}^{-3}$. In the moderately polluted air $72 \%$ of potential cloud nuclei were activated and the average droplet number was $190 \mathrm{~cm}^{-3}$. The difference in the actual cloud droplet number and the number of potential cloud nuclei could be explained by the presence of water-insoluble particles which do not activate. In the heavily polluted air the average droplet concentration was around $320 \mathrm{~cm}^{-3}$ which is, on average, $24 \%$ of the number of potential cloud nuclei. Copyright (C) 1996 Elsevier Science Ltd
\end{abstract}

Key word index: Cloud activation, indirect aerosol effect.

\section{INTRODUCTION}

Clouds play a major role in the radiation balance of the Earth by controlling the amount of incoming short-wave solar radiation and outgoing terrestrial infrared radiation. Clouds form by condensation of water on pre-existing aerosol particles, the so-called cloud condensation nuclei (CCN). The concentration of aerosol particles thus governs the concentration of cloud droplets. Anthropogenic aerosols, produced in large numbers directly and indirectly by industrial emissions, also act as CCN. It has been argued by Twomey (1977) and Wigley (1989) that clouds formed in polluted regions contain more droplets which, according to radiative transfer calculations, leads to an increase in reflection (albedo) of clouds. In contrast, the increased droplet numbers do not lead to higher absorption of infrared terrestrial radiation (Grassl, 1990). Anthropogenic aerosols thus act (in an indirect way) as a radiative cooling factor in the atmospheric radiation balance.

Apart from their effect on the reflection of low marine stratus clouds, increased droplet numbers result in smaller sizes of cloud droplets which inhibits the rain-out of these clouds by drizzle. The persistence of clouds could be the reason for the increased cloudiness over the last decades in coastal regions in Europe (Liepert et al., 1994; Russak, 1990).

Sensitivity ("susceptibility") studies show that the "indirect" aerosol radiative forcing should be most pronounced in marine stratus cloud fields close to polluted continents (Wigley, 1989; Twomey, 1991; Charlson et al., 1992; Platnick and Twomey, 1994). There are two reasons for this. Marine clouds are 
optically thin and there are low numbers of natural nuclei, hence a small number of anthropogenic aerosol has the greatest (relative) influence. Also it was argued that a saturation effect occurs with respect to the numbers of cloud droplets in air with high loadings of aerosol (Jensen and Charlson, 1984; Leaitch et al., 1986; Gillani et al., 1994).

In the assessments of the indirect forcing, only the effect of the (extra) man-made sulphate has been considered (Wigley, 1989; Charlson et al., 1992; Boucher and Lohmann, 1995). A linear relation was assumed between the mass concentration of anthropogenic sulphate and the number concentration of cloud droplets. Leaitch et al. (1986) indeed found, in approximately adiabatic cloud parcels, a linear relation between the mass concentration of sulphate and submicron particle number concentration $(>0.17 \mu \mathrm{m}$ diameter) and a linear relation between cloud droplet number and submicron particle number (less than approximately $750 \mathrm{~cm}^{-3}$ ). This suggested a linear relation between sulphate mass (concentration) and droplet number. However, at aerosol number concentrations higher than $750 \mathrm{~cm}^{-3}$ the droplet number did not increase linearly with the particle number. More recent measurements in more general cloud parcels (Leaitch et al., 1992), using the amount of sulphate in the cloud water as a reference, indicated a strongly non-linear relation between sulphate concentration and droplet number concentration. It should be further appreciated that the above study as well as most of the other studies in the past (Daum et al., 1987; Hegg et al., 1984; ten Brink et al., 1987) were focused on assessing the amount of aerosol sulphate incorporated into clouds rather than on the number of anthropogenic aerosols serving as cloud nuclei.

Outside of Europe several studies were performed in recent years in which activation of the ambient aerosol was studied in terms of number concentrations (Leaitch et al., 1986; Gillani et al., 1994; Anderson et al., 1994; Gras, 1995; Andrea et al., 1995; Hoppel et al., 1994). Novakov and Penner (1993) focused more on assessing the composition of the cloud nuclei and its influence on cloud formation. It should be appreciated, however, that the effect of anthropogenic aerosol on cloud microstructure is a regional phenomenon because of the limited residence time of aerosol particles in the atmosphere. Because of the difference in aerosol characteristics from place to place, results obtained outside of Europe cannot easily be extrapolated to the European aerosol.

In Europe, measurements of the number of particles acting as cloud nuclei in marine air have been recently performed in an airborne cloud study off the coast of England (Martin et al., 1994). The number of aerosol particles before cloud formation was compared with the number of cloud droplets formed in the same air. It was found that in maritime air masses the droplet number concentration was very close to the aerosol number concentration. In air masses, which had passed over land and which had higher aerosol con- centrations, the droplet number concentration was approximately two times less than the aerosol number concentration. The authors suggested that the incomplete activation is due to the presence of hydrophobic material and stressed the importance of chemical characterisation of the aerosol. It should be stressed here that a particle sizer was used which measured the number of particles larger than $0.1 \mu \mathrm{m}$ in diameter. The estimated supersaturations in the study were of the order of $0.3 \%$. At this supersaturation particles as small as $0.06 \mu \mathrm{m}$ act as cloud nuclei. Consequently, the validity of a comparison between measured particle concentration and droplet number concentration is limited. Also in most of the studies mentioned below the aerosol particles were measured with similar aerosol sizers with a similar insufficient lower size limit.

In another recent airborne study near the British Isles (Raga and Jonas, 1995) a comparison was made of the aerosol number concentration and the number of CCN. Also these authors used a particle sizer with a lower threshold at $0.1 \mu \mathrm{m}$. The number of $\mathrm{CCN}$, at $0.8 \%$ supersaturation, was measured with a cloud chamber. At this supersaturation, particles down to $0.035 \mu \mathrm{m}$ in diameter serve as cloud nuclei. Another complication mentioned in the study is the uncertainty in the aerosol number concentration measurement, estimated to be at least $50 \%$. This is an example of the experimental uncertainty in assessing the magnitude of the indirect aerosol effect.

In Europe, apart from the mentioned aircraft studies over the U.K., the cloud properties of orographic ("mountain") clouds were studied. Results from the "Kleiner Feldberg Cloud Experiment" (Hallberg et al., 1994a, b; Svenningsson et al., 1994) are of a more local interest because the experiment was performed at a continental location. Another complication is that in orographic clouds entrainment and mixing processes interfere with the cloud-activation process (Choularton et al., 1986) which complicate a comparison of aerosol number vs cloud droplet number.

In the present study, the cloud-forming properties of marine aerosols in The Netherlands were investigated. The instrumental uncertainties mentioned by others were reduced here by using a large cloud chamber. The advantage of a cloud chamber over in situ measurements is the use of instrumentation which is too delicate for use in aircraft and the possibility to compare, simultaneously, the aerosol before cloud formation, inside the cloud and after cloud processing. Number, size and solubility are the principle factors for particles to serve as cloud condensation nuclei (Pruppacher and Klett, 1978; Twomey, 1977). Consequently, the aerosol was characterized both in terms of its number concentration and size as well as its chemical composition with the emphasis on the amount of soluble material. Since supersaturations in marine clouds are low, in the range of $0.1-0.3 \%$ (Albrecht et al., 1988; Wigley, 1989), special care was taken to establish reproducible, low supersaturations in the chamber. 
At supersaturations common for marine clouds particles larger than approximately $0.06-0.12 \mu \mathrm{m}$ in diameter can be active as $\mathrm{CCN}$. For this reason aerosol monitors capable of accurately measuring these sizes were used. The unique large size of the chamber and the associated high through-put flow allowed unperturbed use of conventional cloud instrumentation, like the Forward Scattering Spectrometer Probe (FSSP-100, PMS Inc.) for sizing and counting of droplets. Also high-flow Berner cascade impactors for chemical analysis of aerosol were used, even inside the chamber. The use of instruments with different measuring principles reduced the uncertainty in the counting of the aerosol particles mentioned by others, see above. Since the processes underlying the droplet formation inside the chamber are different from those occurring in actual clouds, the results of this study can only be considered as a first (maximum) estimate of the influence which anthropogenic aerosols have on droplet numbers in clouds over the North Sea.

\section{EXPERIMENTAL}

\section{Cloud chamber}

The cloud chamber and its characterization have been described in detail elsewhere (Khlystov et al., 1996) and only a summary of the characteristics will be given here. The central part of the chamber is a $30 \mathrm{~m}^{3}$ aluminium vessel (Fig.1). Outdoor air is led into the chamber by a blower at a rate of $30 \mathrm{~m}^{3} \mathrm{~min}^{-1}$. Before entering the chamber the air passes through a humidifier which is maintained several degrees warmer than the room air. After the humidifier the saturated air stream enters a cylindrical vessel of approximately $30 \mathrm{~m}^{3}$ volume. Contacting the colder walls of the vessel, the incoming air becomes supersaturated. The residence time distribution of the air inside the chamber is close to that of a mixed flow reactor. The mean residence time of air and aerosol in the vessel is $1 \mathrm{~min}$. The air leaves the vesse through a tunnel where droplets and not-activated aerosol particles are measured. The very high flow rate enables the use of conventional cloud instrumentation.

Artificially generated pure salt aerosol was used for calibration of the chamber and as reference cloud nuclei for interpretation of the cloud chamber results. The reference aerosol was selected according to the following criteria cloud nuclei consist to a larger part, of sulphate (Twomey, 1977). In anthropogenically influenced air in Western Europe the sulphate is present as ammonium sulphate. Consequently, ammonium sulphate was chosen as the reference aerosol. The calibration tests were done with different aerosol number concentrations but keeping the size distribution constant.

The cloud chamber has proven to be capable of maintaining stable LWC, droplet spectra and supersaturation over extended periods of time (Khlystov et al, 1996). It was found that particles larger than a certain threshold size were activated. The threshold ("cut-of") size was used as a measure of the average supersaturation in the chamber. The supersaturation is controlled by changing the temperature difference between the humidifier and the room air. Typically, supersaturation was set at around $0.15 \%$ by setting the temperature difference at $8^{\circ} \mathrm{C}$. Even though different air parcels have different trajectories and travel time in the chamber and experience different degrees of supersaturation. the cut-off is rather sharp. This is also reflected by narrow size spectrum of the cloud droplets. This proves that the air inside the chamber is well mixed and that the supersaturation is quite uniform. The supersaturation was also estimated from the amount of condensed water (LWC). The supersaturation deduced in this way compared well with the supersaturation derived from the activation threshold size. Sodium sulphate was also used as a reference aerosol for the following reasons. In coastal western Europe, part of the submicron anthropogenic sulphate is present in the form of sodium sulphate (ten Brink et al., 1981). This compound has also been identified in substantial quantities in a recent related study (ten Brink et al., 1995). Sodium sulphate is a result of the reaction between anthropogenic sulphuric acid and natural sea salt ( $\mathrm{NaCl}$ ) (ten Brink et al.. 1981). The previous study (Khlystov et al., 1996) showed that the high deliquescence point of this compound $(97 \% \mathrm{RH})$ does not inhibit cloud activation. In fact, the activation properties of the sodium sulphate were very similar to those of the (more soluble) ammonium sulphate.

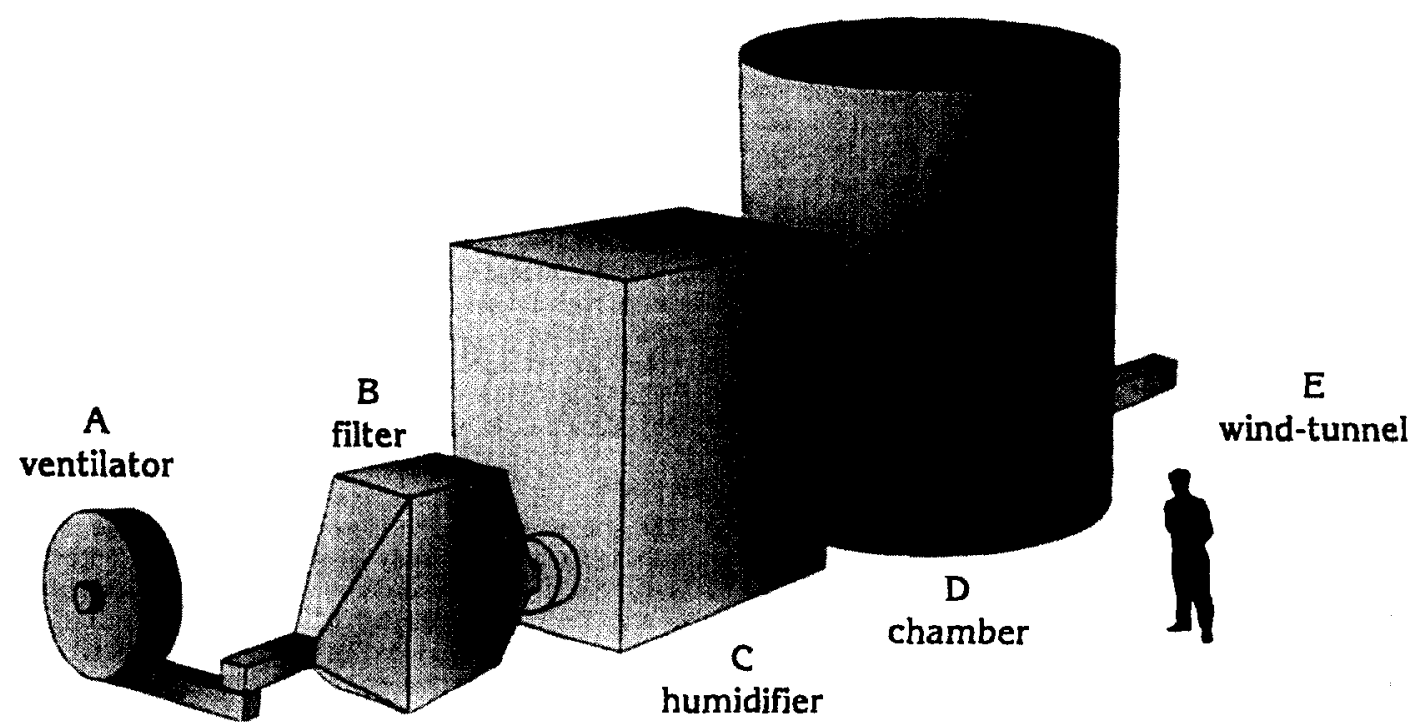

Fig. 1. Sketch of the ECN high flow turbulent cloud chamber (note size). 
Aerosol/droplet monitoring and sampling

The size and number concentration of the incoming aerosol was measured before the chamber with a Differential Mobility Particle Sizer (DMPS. TSI 3071) (ten Brink et al., 1983). The DMPS was set to measure particles from 0.019 to $0.6 \mu \mathrm{m}$ in diameter. The aerosol and the sheath air stream of the DMPS were dried before entering the DMPS with a silica gel diffusion dryer to bring the aerosol to a dry reference state (below the crystallisation point). Aerosol size and number concentration were also measured behind the chamber with another DMPS system. To correct for the residence time inside the chamber, the second DMPS system was sampling with a delay of $1 \mathrm{~min}$ relative to the first DMPS. Before entering the second DMPS the air stream passed an impactor with an $0.8 \mu \mathrm{m}$ cut-off to remove the droplets, then was heated slightly and dried with a silica gel diffusion dryer to bring the aerosol to the dry reference state. In this way the spectrum of inactivated particles is obtained. Comparing the spectra and absolute numbers of the aerosol before and after the chamber the number and size of the activated particles are obtained.

The liquid water content (LWC) of the droplets formed on the aerosol was measured in the tunnel with a PVM-100 probe (Gerber Scientific, Inc.). The PVM-100 probe was calibrated against filter measurements of the liquid water content

The droplet spectra and the number of droplets were measured with an FSSP-100 (Particle Measuring Systems Inc.). Cloud droplets were considered to be those particles that are larger than $2 \mu \mathrm{m}$, an empirical criterion selected by Leaitch et al. (1986). The size calibration of the FSSP was performed with glass beads. The sensing volume of the FSSP was measured with a wire controlled by a micropositione (Dye and Baumgardner, 1984). The droplet concentration was corrected for probe dead time and coincidence error (Baumgardner et al., 1985). The number counting efficiency of the probe was checked by comparing the droplet number with the number of activated aerosol particles found from the aerosol sizer measurements. The numbers did not differ for more than $10 \%$ (Khlystov et al., 1996).

The measurements were evaluated as $1 \mathrm{~h}$ averages. Each data point thus represents an average of four DMPS measurements and 36 FSSP measurements. The standard deviation in the FSSP data over $1 \mathrm{~h}$ was less than $2 \%$.

Also an LAS (Laser Active Spectrometer, PMS), with a lower size limit $(0.1 \mu \mathrm{m}$ in diameter $)$ was used. The LAS measurements gave additional information on the hygroscopic growth of particles which are too small to serve as cloud nuclei, since they have diameters below the activation threshold but which accrete water to grow to sizes several times the original dry size. The instrument measures the size of the wet particles and covers the size "gap" $(0.6-2 \mu \mathrm{m})$ between the measuring ranges of DMPS and FSSP. However, it was found that during the activation tests water condenses in the monitor and that it could only be reliably operated for a limited period of time, typically half an hour. The sizing and counting efficiency of the LAS was compared with that of the DMPS system. The results of the two instruments were comparable within $10 \%$. Even though it is stated by the manufacturer that the upper size limit of LAS is $6 \mu \mathrm{m}$ it was found that due to losses in the sampling line of the instrument it cannot reliably measure the number of particles larger than approximately $2 \mu \mathrm{m}$. Only a small fraction (around $5 \%$ ) of wet particles falls out of the measuring ranges of the DMPS and FSSP (Fig. 2).

Cascade impactors were used for collecting the aerosol as a function of size for weighing and chemical analysis (Berner, 1989). These eight-stage Berner impactors have a high size resolution and are capable of sampling aerosol down to $0.06 \mu \mathrm{m}$ in diameter. In our study three impactors were used, two for collection of the aerosol and one for the droplets: one was placed before the chamber, one inside and one after the chamber. The impactor measurements required

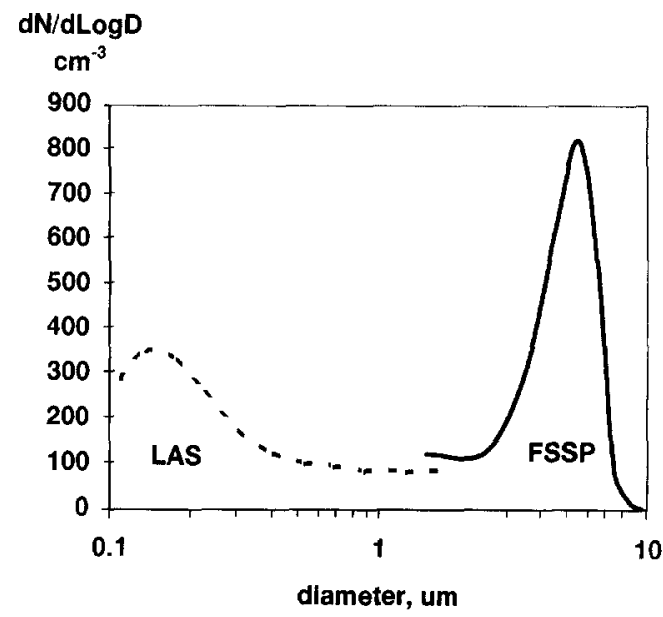

Fig. 2. Example of the droplet $(>2 \mu \mathrm{m})$ spectra as measured with FSSP cloud droplet monitor and "wet" aerosol spectra after the cloud chamber measured with LAS-X optical counter.

Table 1. Dry diameters of the smallest particles that activate at $0.15 \%$ supersaturation as a function of mass fraction of soluble material

Mass fraction of soluble material Dry diameter $(\mu \mathrm{m})$

\begin{tabular}{ll}
\hline 1.00 & 0.10 \\
0.10 & 0.21 \\
0.01 & 0.44 \\
\hline
\end{tabular}

the presence of personnel of the University of Vienna; consequently, impactor data were only available for a limited number of activation tests. Aerosol samples were collected on aluminium foils. After collection the samples were weighed with a precision balance ( $1 \mu \mathrm{g}$ accuracy), then dissolved in $7 \mathrm{ml}$ of doubly demineralized water and analysed for soluble inorganic species with ICP and AAS.

The size and the insoluble material content of a particle govern its activation (Pruppacher and Klett, 1978; Twomey, 1977). Particles with a higher content of insoluble material need to be substantially larger to be activated (Table 1). In our measurements the amount of insoluble material was deduced by subtracting the mass of soluble material from the total aerosol mass. It should be noted that measuring the composition of the smallest, most numerous cloud nuclei is very difficult since even though they represent the majority of the number they contain very little mass. Sampling for several hours provides an aerosol deposit in the smallest impactor stage with a mass of the order of a few micrograms which is comparable to the weighing error. To cope with this problem we extrapolated the composition measured at larger diameters to lower sizes, analogous to the extrapolations of Novakov and Penner (1993).

\section{Approach}

The site where the measurements were carried out is ideally located for a study of marine aerosol, since it is situated directly on the border of the North Sea $(200 \mathrm{~m}$ from the shore line). The measurements were confined to the air masses coming from the sea (SW-N wind directions) (Fig. 3). The activation properties of the clean marine aerosol, in arctic N-NW air flows, were compared with those of the marine aerosol polluted with anthropogenic emissions. An increase in cloud nuclei (due to anthropogenic aerosol) is 


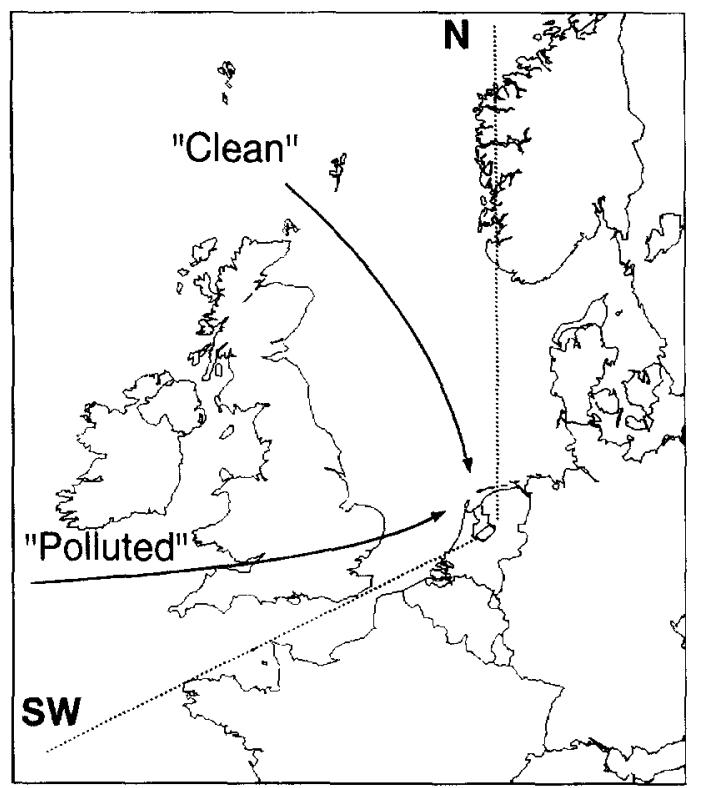

Fig. 3. Classification of air mass types according to wind direction.

expected in air coming from the direction of the U.K. (SW-W). The difference in the number of activated particles in these two air flows is a first measure of the influence of anthropogenic aerosol on cloud formation. Activation tests reported here were performed in the spring-autumn periods of 1993 and 1994. Table 2 gives a short description of the weather conditions during the measurements.

To characterise the influence of the anthropogenic aerosols on marine clouds it is necessary to find a "baseline" which represents clean marine aerosol. As was discussed above, clean marine aerosol is expected in air flows coming from the sea which did not pass over the British Isles (air trajectories from the $\mathrm{NW}$ ). The measurements showed that with the same wind direction the aerosol number can vary rather strongly from day to day, presumably because of different air mass histories. Backtrajectories help to understand the origin of the air mass, but are very often not sufficiently precise. Therefore, it was decided to use the total aerosol number concentration for characterisation of air masses.

The lowest total (from $0.02 \mu \mathrm{m}$ in diameter) aerosol number concentration encountered at the site was around 100 $\mathrm{cm}^{-3}$. Consequently, it was decided that "clean" marine air masses have total aerosol concentrations of the order of $100 \mathrm{~cm}^{-3}$. Hoppel et al. (1990) reported mean total aerosol number concentrations in the remote Atlantic of around $200 \mathrm{~cm}^{-3}$ with the lowest observed concentration being $100 \mathrm{~cm}^{-3}$. Andrea et al. (1995) in a study in South Atlantic (which might not be indicative for North Atlantic background aerosol) observed concentrations as low as $50 \mathrm{~cm}^{-3}$ with the mean concentrations during "clean" conditions being around $220 \mathrm{~cm}^{-3}$. Since references to lower aerosol concentrations were not found in the literature, the lowest observed value at our site seems justified as being representative for marine background aerosol. Higher aerosol concentrations were attributed to the class of "polluted" air masses. The polluted air masses were further divided into "moderately" and "heavily" polluted according to the total aerosol concentrations. Air masses with number concentrations of the order of $1000 \mathrm{~cm}^{-3}$ were attributed to the "moderately" polluted class and with concentrations of the order of $10,000 \mathrm{~cm}^{-3}$ to the "heavily" polluted class. This classification is rather arbitrary.

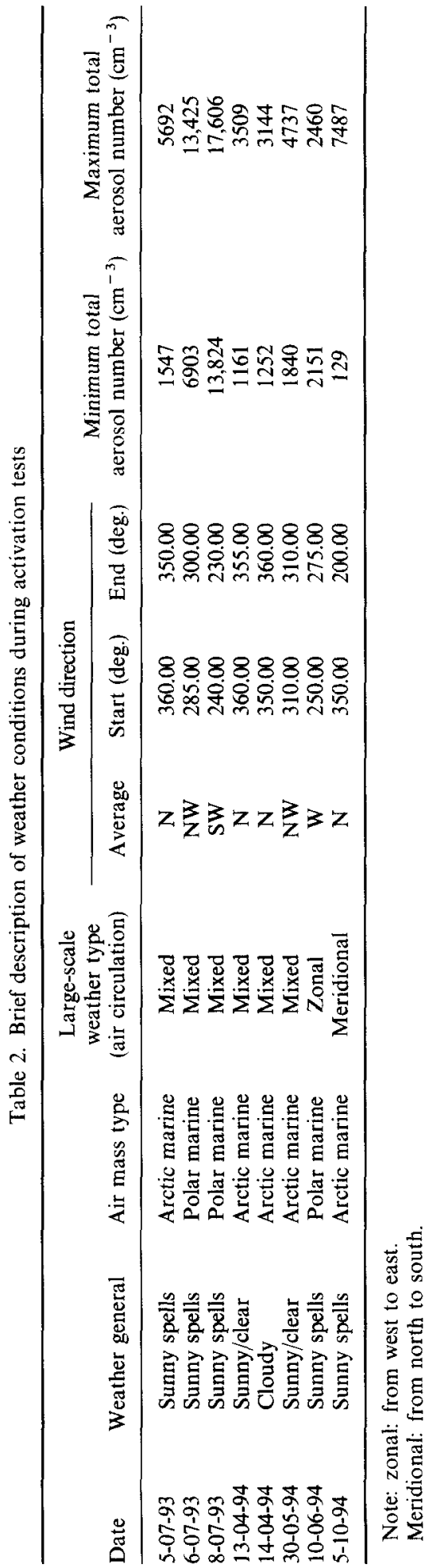




\section{Potential cloud nuclei}

In the next section the term potential cloud nuclei ( $\mathrm{PCN}$ ) will be used and its definition is given here. Potential cloud nuclei are those particles which, according to their size. would act as cloud nuclei at a given supersaturation, but it is the amount of insoluble material in them that determines whether they actually act as such. In other words, potential cloud nuclei are those (ambient) particles which are larger than the activation threshold as determined with the reference sulphate aerosol at the same supersaturation.

The number of actual cloud nuclei is equal to the number of droplets formed in the chamber and this number is compared with the number of potential cloud nuclei. Differences in the numbers, as discussed in more detail in the next section, are due to the fact that the aerosol often contains insoluble material. The number of potential cloud nuclei is equal to the number of particles larger than the threshold size. The uncertainty in the number of potential cloud nuclei, caused by the spread in cut-off diameter in the chamber (Khlystov et al., 1996), is estimated as $15 \%$. The uncertainty in the actual cloud number concentration is $10 \%$ or less (Khlystov et al., 1996). Thus, the combined error is of the order of $20 \%$.

\section{RESULTS AND DISCUSSION}

\section{Droplet number concentrations}

Activation tests, performed in the spring-autumn periods of 1993 and 1994, show that the droplet number concentration did not exceed $500 \mathrm{~cm}^{-3}$ on any of the days, even though the total aerosol number concentration in the polluted air masses was as high as $17,600 \mathrm{~cm}^{-3}$. The results are further broken down for a proper evaluation according to the criteria given in

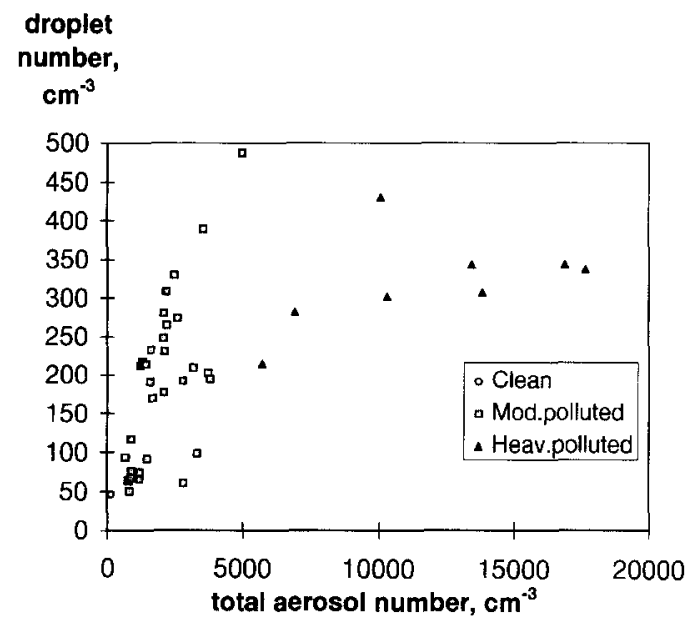

Fig. 4. Droplet number vs total aerosol number in marine air mass types, as defined in text. the previous section. This means that three categories of marine aerosol were distinguished, viz, clean, heavily polluted and moderately polluted.

The droplet number vs the total aerosol number for the three categories is given in Fig. 4. The average number of particles and the average number of cloud droplets formed (particles activated) for the three air types are given in Table 3. It is seen that the aerosol number concentrations increases with a factor of 90 going from clean to heavily polluted air but the number of droplets only increases with a factor of seven.

At the supersaturations used in this study the threshold for activation is around $0.1 \mu \mathrm{m}$, see the previous section. The aerosol spectra (Fig. 5) show that a large number of particles has sizes below this activation threshold. Consequently, the total aerosol number
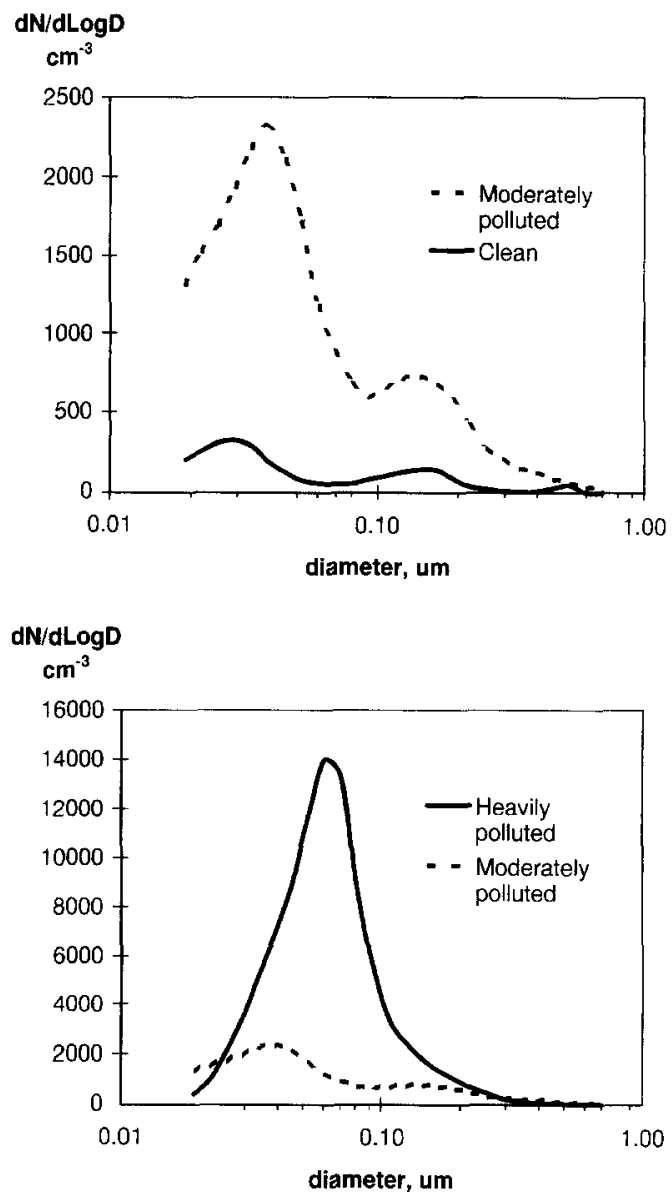

Fig. 5. Comparison of aerosol spectra in clean, moderately polluted and heavily polluted air masses. Notice the differences in spectral shape and absolute number concentrations.

Table 3. Average droplet number concentration vs total aerosol number concentration (units, $\mathrm{cm}^{-3}$ )

\begin{tabular}{lrcc}
\hline & Clean & Moderately polluted & Heavily polluted \\
\hline Total aerosol & 129 & 1991 & 11,828 \\
Droplets & 45 & 191 & 322 \\
\hline
\end{tabular}


overestimates the number of droplets. For a proper assessment of the number of cloud active nuclei in the ambient aerosol the number of potential cloud nuclei (particles larger than the threshold, see Approach section in the previous section) was used. The comparison between the droplet number and the number of potential cloud nuclei is given in Fig. 6 and Table 4. As seen from Fig. 6 the droplet number is not equal to the potential cloud nuclei number (the one-to-one

(A)

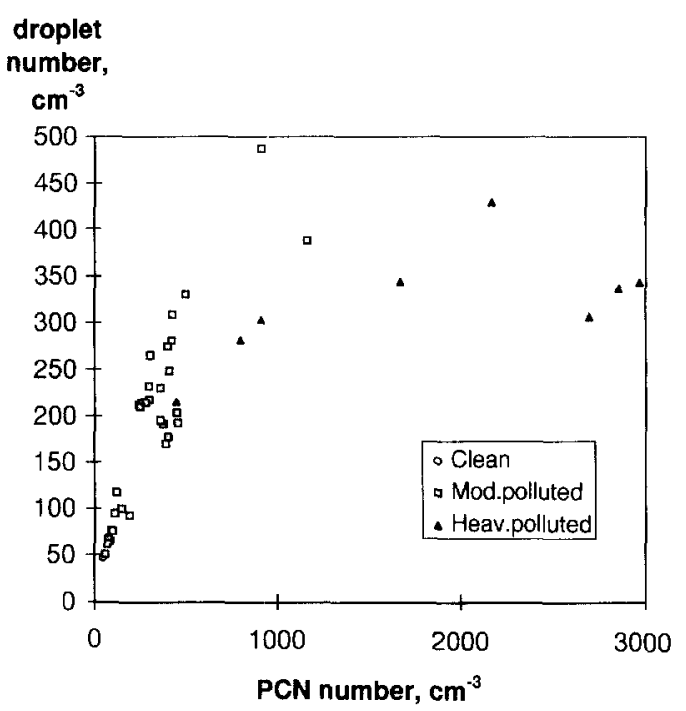

(B)

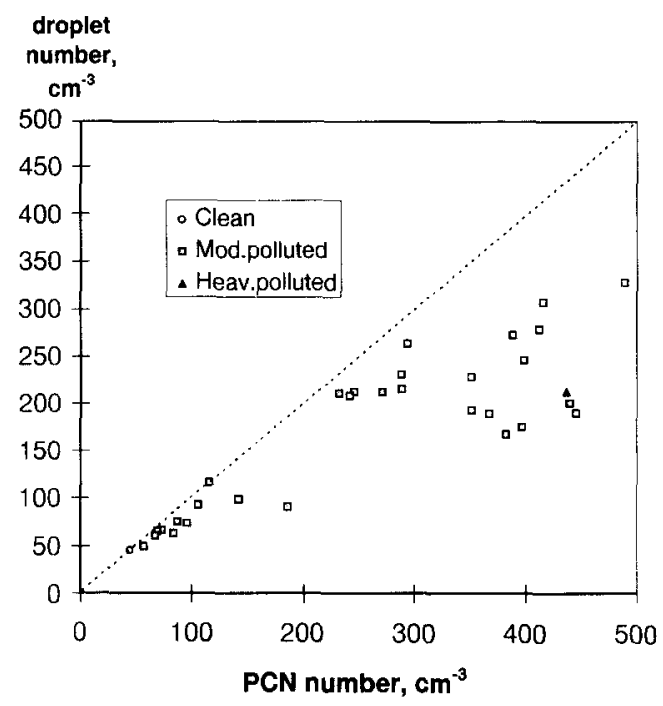

Fig. 6. Droplet number vs number of potential cloud nuclei in the three air types: (A) full range of concentrations; (B) region of low number concentrations. line) except for a few points with low aerosol numbers. The reason that not all potential cloud nuclei are activated is explained below, in the separate sections for each air mass type.

\section{Clean air}

During the period of measurements only one point satisfied the criteria of the clean air mass class. The total aerosol number concentration was $129 \pm 1$ $\mathrm{cm}^{-3}$. The droplet number concentration $(45 \pm 4$ $\mathrm{cm}^{-3}$ ) was equal to the number concentration of potential cloud nuclei. Figure 7 shows the aerosol spectra before and after the activation. Due to a spread in supersaturations in the chamber there is a small fraction of particles larger than the threshold which are not activated and a small fraction of particles with sizes smaller than the threshold which are activated. This is similar to the activation pattern of the reference ammonium sulphate aerosol (Khlystov et al., 1996). The potential cloud nuclei which were not activated were assessed in a similar way to the procedure for assessing the number of PCN described earlier in this paper. Subtracting the spectrum expected after the chamber from the actually found one, the spectrum of non-activated particles is obtained. This exercise shows that all potential cloud nuclei are indeed activated. A different situation was found in the polluted air masses.

\section{Heavily polluted air}

The total aerosol number concentration in the heavily polluted air, defined as air in which the total particle number concentration is of the order of $10,000 \mathrm{~cm}^{-3}$, was between 5700 and $18,000 \mathrm{~cm}^{-3}$.

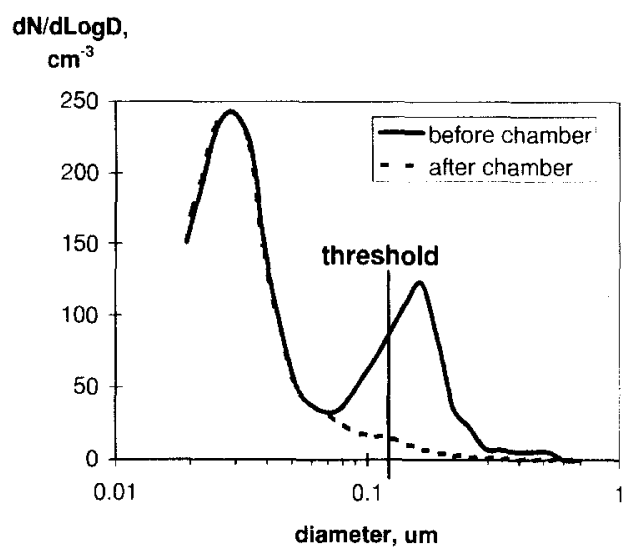

Fig. 7. Aerosol activation in clean air masses.

Table 4. Average droplet number concentration vs number concentration of potential cloud nuclei (units, $\mathrm{cm}^{-3}$ )

\begin{tabular}{lccc}
\hline & Clean & Moderately polluted & Heavily polluted \\
\hline Potential cloud nuclei & 45 & 307 & 1808 \\
Droplets & 45 & 191 & 322 \\
\hline
\end{tabular}


The number concentration of droplets after activation was $215-430 \mathrm{~cm}^{-3}$. This is on average $24 \%$ of the potential cloud nuclei $\left(440-2970 \mathrm{~cm}^{-3}\right)$. The fact that only one out of four potential cloud nuclei are actually activated can be explained for the better part by the so-called "saturation" effect. This effect is caused by the fact that the nuclei compete for the available water vapour. A saturation effect of similar magnitude was also found in the reference tests with the artificial aerosol at similar number concentrations (Khlystov et al., 1996).

\section{Moderately polluted air masses}

The total number concentration in the moderately polluted air masses, classified as those situations with the total particle number concentration of the order of $1000 \mathrm{~cm}^{-3}$, was between 640 and $4930 \mathrm{~cm}^{-3}$. The number concentration of potential cloud nuclei varied from 57 to $1151 \mathrm{~cm}^{-3}$. On average, $72 \%$ of the potential cloud nuclei were activated with the average droplet number being $191 \mathrm{~cm}^{-3}$ (Table 4).

At low PCN numbers up to $96 \%$ were activated. On some occasions, though, the droplet number was as high as $265 \mathrm{~cm}^{-3}$, equal to $90 \%$ of the number of potential cloud nuclei. This indicates that at these potential nuclei number concentrations the "saturation" effect, discussed above, does not occur. The most probable reason that some of the potential cloud nuclei are not activated is that they are completely insoluble or consist to a great extent of insoluble material. This explanation is supported by the content of insoluble material in the aerosol of this class of which an example is given in Fig. 8. Due to the very little aerosol mass it is not possible to assess the insoluble material content on the impactor stage with $0.15 \mu \mathrm{m}$ cut-off diameter and for this reason only the error bar in the measurement is given. Extrapolation from the larger sizes suggests that up to $40 \%$ of the aerosol mass is insoluble in the potential cloud nuclei size range. Further evidence that a substantial part of

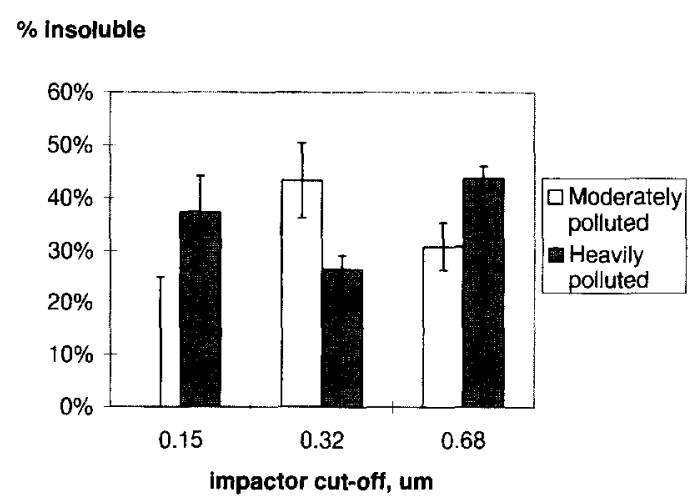

Fig. 8. Insoluble material content in the potential cloud nuclei size range in both moderately and heavily polluted air masses. Error bars indicate the uncertainty in the mass/composition measurements. the particles is insoluble comes from the composition data gathered with the impactor in the heavily polluted air.

The impactor data do not provide information on how the insoluble material is distributed among the individual particles (internal or external mixing of soluble and insoluble material). However, from the number and size of the inactivated particles (Fig. 9) the volume of insoluble material in the cloud nuclei size range can be deduced. These estimates show that the non-activated particles comprise $25-30 \%$ of the total volume in its size range. Assuming that the density of all particles is the same we can compare the estimated mass fraction of not activated particles with the mass fraction of insoluble material found from the impactor measurements. The impactor measurements give $20-40 \%$ insoluble content. From the fact that the two values are comparable it is concluded that, for the better part, the "insoluble" material is not mixed with the soluble material.

Svenningsson et al. (1994) in a study of continental clouds in Germany found that approximately half of the aerosol particles contained less than $5 \%$ of soluble material. Okada et al. (1990) in a study of the nucleation properties of ambient aerosol in Japan found that up to $30 \%$ of the particles in the size range $0.1-0.33 \mu \mathrm{m}$ were not activated even at $1 \%$ supersaturation. Those particles were similar in structural features to carbon particles or made up of a central soluble core covered with a layer of insoluble (organic) material.

\section{Aerosol size spectra}

A comparison of the aerosol size spectra which are characteristic for clean, moderately polluted and heavily polluted air masses (as defined in the previous section) is shown in Fig. 5. With each of the three air mass types discussed above, different aerosol spectra

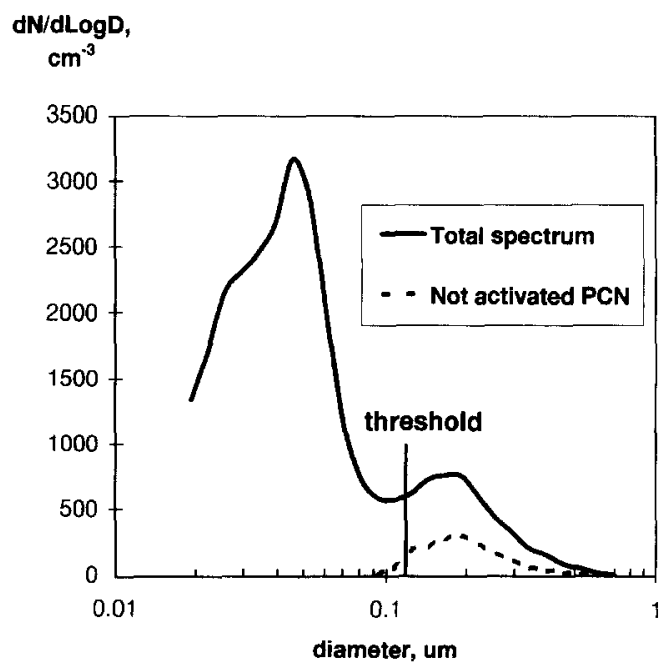

Fig. 9. Aerosol activation in the moderately polluted air masses. 
are associated. Both moderately polluted and clean air mass types have a bimodal number distribution with one mode centred at around $0.035 \mu \mathrm{m}$ and the other mode at around $0.15 \mu \mathrm{m}$. The moderately polluted aerosol has a more pronounced first mode. In the heavily polluted class the two modes are usually not clearly separated and the spectrum tends, with increasing total number concentrations, to become uni-modal, centred between 0.05 and $0.1 \mu \mathrm{m}$. One should bear in mind that our classification of air mass types according to the total number concentration is rather arbitrary and, consequently, there is no definite boundary between the classes, though, the above spectral characteristics of each class usually hold to be true.

\section{Chemical composition}

The impactor measurements show that the watersoluble inorganic fraction of the aerosol in the proper size range is dominated by sulphate, which is a justification for the use of artificial sulphate salts in the characterisation/reference tests (Khlystov et al., 1996). The particles of approximately $0.5 \mu \mathrm{m}$ diameter are in part composed of sodium sulphate (ten Brink et al., 1995). The reference tests showed that the activation (cloud forming) properties of this compound are similar to those of ammonium sulphate (Khlystov et al., 1996).

\section{Comparison with aircraft studies}

A comparison of the chamber results with actual measurements from aircraft is by nature focused on those studies performed in marine air in the vicinity of and over the U.K. by Martin et al. (1994). The best conditions for a comparison of the chamber tests and actual cloud measurements would be those at cloudbase, where the residence time of the air in the actual cloud is similar to the residence time of the air in the chamber. However, at cloud-base, Martin et al. (1994) notice a substantial variation in the cloud droplet number. Therefore, we compare our results with droplet numbers at a location somewhat higher up in the cloud.

The maximum droplet number concentration observed by Martin et al. (1994) in polluted marine air masses did not exceed $500 \mathrm{~cm}^{-3}$, which is consistent with our observations. In air masses with low aerosol number, Martin et al. (1994) found that the droplet number was equal to the aerosol number which was also found in the present measurements in the clean air. As Martin et al. (1994) measured only aerosol particles larger than $0.1 \mu \mathrm{m}$, the cloud droplet number was occasionally higher than the aerosol number. Our experiments with ammonium sulphate aerosol (Khlystov et al., 1996) show that at supersaturations higher than $0.15 \%$, the number of aerosol particles larger than $0.1 \mu \mathrm{m}$ underestimates the number of cloud nuclei. One can expect that at a higher supersaturation, which can be encountered in clouds, even smaller particles can be activated.
It should be noted that even though the results of our experiments are similar to those of the actual cloud measurements, the processes of cloud formation in our chamber may differ from those occurring in real clouds. Since simulation of the processes inside the chamber is very difficult, a comparison with measurements in the actual clouds above the measurement site is required. Such a comparison is foreseen in the future.

\section{CONCLUSIONS}

In "clean" marine air all particles larger than the activation size threshold were activated.

The number of cloud droplets formed in the polluted marine air, typically around $250 \mathrm{~cm}^{-3}$ (with a maximum of $490 \mathrm{~cm}^{-3}$ ), was a factor of five higher than that in the "clean" marine air.

In "heavily" polluted marine air masses a small fraction of the number of particles in the cloud nuclei size range was activated, due to limitations in the amount of available water (saturation effect) and the presence of insoluble material.

In "moderately" polluted marine air on some occasions practically all particles in the cloud nuclei size range were activated. In other tests from 10 to $65 \%$ of the potential cloud nuclei did not activate because they were insoluble.

The amount of insoluble material is a key factor in the activation of aerosol particles. It needs further quantification with respect to composition and sources. It should be considered, though, that chemical analysis of the particles in the cloud nuclei size range is very difficult since they represent very little mass.

The number of aerosol particles activated in the chamber tests was in good agreement with the number of activated particles in actual marine stratus over and near the U.K.

Acknowledgements - The study was financed in part by the Dutch National Research Program on Global Air Pollution and Climate Change (NOP project no. 852066). The other part of the financial support came from the Department of Economic Affairs of The Netherlands (ECN-contract no. 2677). The authors are thankful to Dr Richard Leaitch for his useful comments during preparation of this paper

\section{REFERENCES}

Albrecht B. A., Randal D. A. and Nicholls S. (1988) Observations of marine stratocumulus clouds during FIRE. Bull. Am. Met. Soc. 69, 618-626.

Anderson T. L., Covert D. S. and Charlson R. (1994) Cloud droplet number studies with a counterflow virtual impactor. J. geophys. Res. 99, 8249-8256.

Andrea M. O., Elbert W. and de Mora S. J. (1995) Biogenic sulfur emissions and aerosols over the tropical South Atlantic. 3. Atmospheric dimethylsulfide, aerosols and cloud condensation nuclei. J. geophys. Res. 100 , $11,335-11,356$. 
Baumgardner D., Strapp J. W. and Dye J. E. (1985) Evaluation of the forward scattering spectrometer probe. Part II: corrections for coincidence and dead time errors. $J$. atmos. Oceanic Technol. 2, 626632.

Berner A. (1989) Haze and its relation to the atmospheric accumulation aerosol. Sci. Total Envir. 86, 251-261.

Boucher O. and Lohmann U. (1995) The sulfate-CCN-cloud albedo effect. A sensitivity study with two general circulation models. Tellus 47B, 281-300.

Charlson R. J., Schwartz S. E., Hales J. M., Cess R. D., Coakley J. A. Jr, Hansen J. E. and Hofmann D. J. (1992) Climate forcing by anthropogenic aerosols. Science 43, $152-163$.

Choularton T. W., Consterdine I. E., Gardiner B. A., Gay M. J., Hill M. K., Latham J. and Stromberg I. M. (1986) Field studies of the optical and microphysical characteristics of clouds enveloping Great Dun Fell. $Q . J / R$. Met. Soc. 112, 131-148.

Daum P. H., Kelly T. J., Strapp J. W., Leaitch W. R., Joe P., Schemenauer R. S., Isaac G. A., Anlauf K. G. and Wiebe H. A. (1987) Chemistry and physics of a winter stratus cloud layer: a case study. J. geophys. Res. 92, 8426-8436.

Dye J. E. and Baumgardner D. (1984) Evaluation of the forward scattering spectrometer probe. Part I: electrical and optical studies. J. atmos. Oceanic Technol. 1, 229-344.

Gillani N. V., Leaitch W. R., Strapp J. W. and Isaac G. A. (1994) Field observations in continental stratiform clouds: partitioning of cloud particles between droplets and unactivated interstitial aerosols. J. geophys. Res. (submitted).

Gras J. L. (1995) CN, CCN and particle size in southern ocean air at Cape Grim. Atmos. Res. 35, 233-251.

Grassl H. (1990) Aerosols and climate. In Proc. Symp. World Climate and Aerosols, Bunnik, May 1990 (edited by van de Vate J. F. and Tirion H. B.), ver. LUCHT, p. 5.

Hallberg A., Noone K. J., Ogren J. A., Svenningson I. B., Flossman A., Wiedensohler A., Hanson H.-C., Heintzenberg J., Anderson T. L., Arends B. G. and Maser R. (1994a) Phase partitioning of aerosol particles in clouds at Kleiner Feldberg. J. atmos. Chem. 19, 107-127.

Hallberg A., Ogren J. A., Noone K. J., Okada K., Heintzenberg J. and Svenningson I. B. (1994b) The influence of aerosol particle composition on cloud droplet formation. J. atmos. Chem. 19, 153-171.

Hegg D. A., Hobbs P. V. and Radke L. F. (1984) Measurements of the scavenging of sulfate and nitrate in clouds. Atmospheric Environment 18, 1939-1946.

Hoppel W. A., Fitzgerald J. W., Frick G. M., Larson R. E. and Mack E. J. (1990) Aerosol size distributions and optical properties found in the marine boundary layer over the Atlantic Ocean. J. geophys. Res. 95, 3659-3686.

Hoppel W. A., Frick G. M., Fitzgerald J. W. and Larson R. E. (1994) Marine boundary layer measurements of new particle formation and the effects nonprecipitating clouds have on aerosol size distribution. J. geophys. Res. 99, $14,443-14,459$.

Jensen J. B. and Charlson R. J. (1984) On the efficiency of nucleation scavenging. Tellus 36B, 367-375.

Khlystov A., Kos G. P. A. and ten Brink H. M. (1996) A high flow turbulent cloud chamber. Aerosol Sci. Technol. (in print).
Leaitch R., Strapp J. W. and Isaac G. A. (1986) Cloud droplet nucleation and cloud scavenging of aerosol sulphate in polluted atmospheres. Tellus 38B, 328-344.

Leaitch R., Isaac G. A., Strapp J. W., Banic C. M. and Wiebe H. A. (1992) The relation between cloud droplet number concentration and anthropogenic pollution: observations and climatic implications. J. geophys. Res. 97, $2463-2474$

Liepert B., Fabian P. and Grassl H. (1994) Solar radiation in Germany-observed trends and an assessment of their causes. Part I: regional approach. Beitr. Phys. Atmos. 67, 15-29.

Martin G. M., Johnson D. W. and Spice A. (1994) The measurement and parameterization of effective radius of droplets in warm stratiform clouds. J. atmos. Sci. 51, $1823-1842$.

Novakov T. and Penner J. E. (1993) Large contribution of organic aerosols to cloud-condensation-nuclei concentrations. Nature 365, 823-826.

Okada K., Tanaka T. and Naruse H. (1990) Nucleation scavenging of submicrometer aerosol particles. Tellus 42B, 463-480.

Platnick S. and Twomey S. (1994) Determining the susceptibility of cloud albedo to changes in droplet concentration with the advanced very high resolution radiometer. J. appl. Met. 33, 334-347.

Pruppacher H. R. and Klett J. K. (1978) Microphysics of Clouds and Precipitation. Reidel, Dordrecht.

Raga G. B. and Jonas P. R. (1995) Vertical distribution of aerosol particles and CCN in clear air around the British Isles. Atmospheric Environment 29, 673-684.

Russak V. (1990) Trends of solar radiation, cloudiness and atmospheric transparency during recent decades in Estonia. Tellus 42B, 206-210.

Svenningsson B., Hanson H.-C., Wiedensohler A., Noone K., Ogren J., Hallberg A. and Colvile R. (1994) Hygroscopic growth of aerosol particles and its influence on nucleation scavenging in cloud: experimental results from Kleiner Feldberg. J. atmos. Chem. 19, 129-151.

ten Brink H. M., Mallant R. K. A. M. and de Vate J. F. (1981) $\mathrm{SO} 2$ conversion in a marine atmosphere. Part 2. In Physico-Chemical Behaviour of Atmospheric Pollutants (edited by Versino B. and Ott H.), p. 319. Reidel, Dordrecht.

ten Brink H. M., Plomp A., Spoelstra H. and van de Vate J. F. (1983) A high-resolution electrical Mobility Aerosol Spectrometer (MAS). J. aerosol Sci. 14, 589.

ten Brink H. M., Schwartz S. E. and Daum P. H. (1987) Efficient scavenging of acrosol sulfate by liquid-water clouds. Atmospheric Environment 21, 2035-2052.

ten Brink H. M., Kos G. P. A., Arends B. G. and Veefkind J. P. (1995) ECN contribution to reduction of solar radiation by manmade aerosol in Europe. Report on ECproject EV5V-CT92-0171. ECN-C-95-082. ECN, Petten.

Twomey S. (1977) Atmospheric Aerosols. Elsevier, New York.

Twomey S. (1991) Aerosols, clouds and radiation. Atmospheric Environment 25A, 2435-2442.

Wigley T. M. L. (1989) Possible climate change due to $\mathrm{SO}_{2}$ derived cloud condensation nuclei. Nature 339, 365. 